\title{
Applications of cellulose nanomaterials in pharmaceutical science and pharmacology
}

\author{
Y. $\mathrm{CaO}^{*}$
}

SSCI, a Division of Albany Molecular Research Inc., 3065 Kent Ave, IN 47906, West Lafayette, USA

Received 25 January 2018; accepted in revised form 3 April 2018

\begin{abstract}
Cellulose nanomaterials (CNs) have been successfully applied to a variety of scientific areas in recent years with remarkable engineering utilities. As sustainable materials of huge abundance, CNs show significant potentials in fine-tune the microstructures and kinetics from the nano-level. This paper reviews recent key advancements of the use of CNs in the fields of pharmaceutical science and pharmacology. A broad overview of the development of CNs is provided, and the current methods to obtain the materials are discussed. The different types of processing techniques are reviewed, that are critical to the applications in pharmaceutical science and pharmacology. The key breakthroughs of applications in major fields are discussed, including oral administration, topical administration, tissue scaffolds, and antibacterial applications.
\end{abstract}

Keywords: nanomaterials, cellulose nanofibril, cellulose nanocrystal, processing, application

\section{Introduction}

Cellulose is the ubiquitous and most important structural and reinforcing component in plants. It is also found from bacteria, fungi, algae, amoebas, and sea animals [1]. The vast abundance and renewability of cellulose make it an 'almost inexhaustible' $[2,3]$ material. It has been widely claimed by numerous researchers as the most abundant renewable biopolymer [4], natural polymer [5, 6], natural organic biomaterial [7], biomass [8], biopolymer [9, 10], natural polysaccharide [11], and renewable natural biopolymer [12]. Other prominent attributes of cellulose include multifunctionality [13], chemical stability and derivatizability [5], lightweight, high aspect ratio, excellent mechanical properties, low density, low coefficient of thermal expansion, functionalizable surface, and carbon neutrality [9]. The monomer of cellulose contains three hydroxyl groups, resulting in high hydrophilicity and hygroscopicity. More importantly, the abundance of the hydroxyl groups makes cellulose conveniently surface-modifiable, and therefore it is versatile in different applications. Figure 1 presents the chemical structure of cellulose.

The advantages bring the cellulose-based materials the unparallel potential in a variety of applications, considering the environmental concerns and nonrenewable nature of the petroleum based materials and synthetic fibers, e.g., carbon nanotubes. Under the dual threats of the consumption of the non-renewable resources and the environmental problems caused by the petroleum-based polymers, the versatility and sustainability make cellulose the natural solution for human beings and this planet. According to a 2006 report, the total volume of cellulose is approximately 700 billion tons and the natural renewal

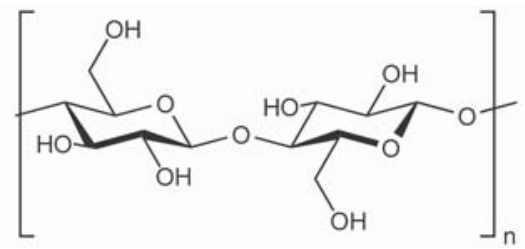

Figure 1. Chemical structure of cellulose 


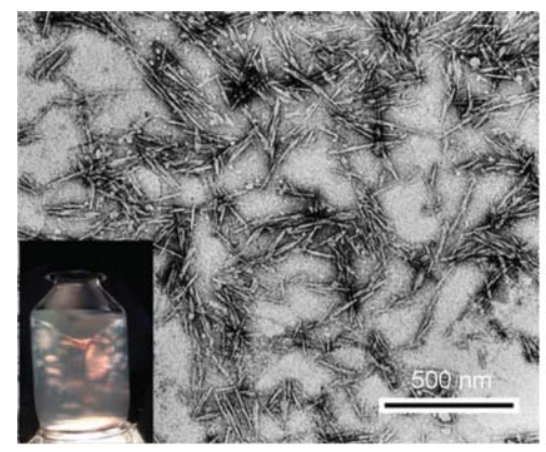

a)

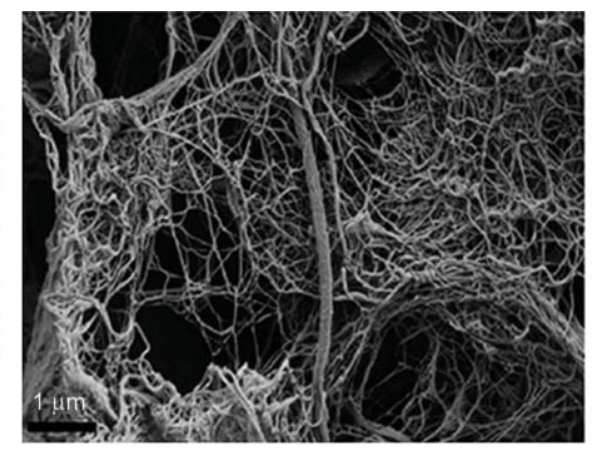

b)

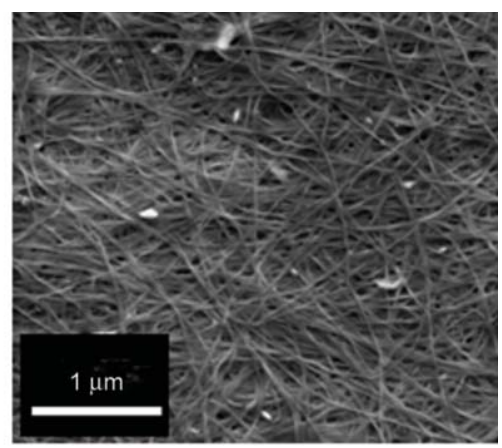

c)

Figure 2. (a) Transmission electron image of CNC from wood pulp (scale bar: $500 \mathrm{~nm}$ ). Inset: aqueous dispersion of wood pulp CNC (0.1 wt\%) placed between cross-polarizers (image reproduced from [22] with permission), (b) SEM image of CNF, scale bar is $1 \mu \mathrm{m}$, (image reproduced from [23] with permission), (c) SEM image of BC produced from Acetobacter xylinum (ATCC 23769), (image reproduced from [24] with permission).

is 40 billion/year [14]. In spite of the massive giving by the nature, 0.2 billion was used as the starting materials for future utilization. In the document The Technology Roadmap for Plant/Crop-Based Renewable Resources 2020 by U.S. Department of Energy, a goal has been set that at least $10 \%$ of basic chemical building blocks will arise from plant-derived renewables by 2020 , with a further increase to $50 \%$ by 2050 [15]. It has been a worldwide effort to explore the renewable resources to benefit many aspects of our daily life.

In the last few decades, the term nano has been arising with vast presence in quite a few scientific disciplines. It is simply fascinating due to the fact that human beings may design, modify, and control small elements/units at such small scale, in an effort to generate properties, performances, and functionalities at the macroscopic level for a variety of purposes. In the last two decades, the research on cellulose nanomaterials (CNs) started radically pursuing the utility of cellulose at the nanoscale, as well as understanding their behavior with respect to the fundamental science. A common consensus on the definition of nanomaterials is a geometry with at least one dimension less than $100 \mathrm{~nm}[16,17]$. Under this scope, there are three major CNs, cellulose nanofibril (CNF), cellulose nanocrystal (CNC), and bacterial cellulose (BC) [18]. CNFs are most often considered as an aggregation of 10-50 elementary fibrils with a web-like structure [19]. CNCs are the highly crystalline regions in the CNFs. Despite the fundamental difference in crystallinity from $\mathrm{CNC}, \mathrm{CNF}$ contains cellulose chains with varying degrees of order [20]. The BCs normally have higher average molecular weight, crystallinity, and different surface chemistry than plant CNFs. Despite the identical molecular formula, $\mathrm{BC}$ does not present groups such as carbonyl and carboxyl units that can be found from plant cellulose [21]. However BCs may possess superior properties such as high purity, high degree of polymerization, high crystallinity $(70 \sim 80 \%)$, and high water content of up to $90 \%$. The current costs for CNF and CNC are 1.8 and $1.0 \mathrm{USD} / \mathrm{g}$, respectively (freeze dried powder, price from a major US manufacturer, 01/2018). The costs are approximately similar to carbon nanotubes. Fortunately, considering the high abundance of cellulose in the nature (while carbon nanotube is man-made material) and the developing technology to extract cellulose from a variety of sources, the numbers may be declining significantly in the near future. The declining costs are more than nontrivial to step up from the laboratory phase to the real-world applications. Figure 2 provides typical microstructural images of the three types of CNs.

Figure 3 presents the number of academic publications with relevant keywords in the title, acquired from ScienceDirect. The research in these fields has enjoyed a remarkable increasing attention. It is noteworthy that different names have been referred to the same $\mathrm{CN}$ by different researchers. The lack of consistency in nomenclature has cost plenty of efforts to search, understand, and cross-check different materials. The terms that have been used include cellulose nanocrystal [25], cellulose nano-crystal [26], cellulose nanocrystalline [27], crystalline cellulose nanofibril [28], nano-fiber [29] nano-cellulose [30] nanocrystalline cellulose [31], cellulose nanofibril [20], nanofibrillated cellulose [6], nanofibrillar cellulose [32], nano-fibrillated cellulose [33], cellulose nanofiber [34]. The subjective use of different terms for the same material may lead to confusion, misunderstanding, and miscommunication in this domain area, 


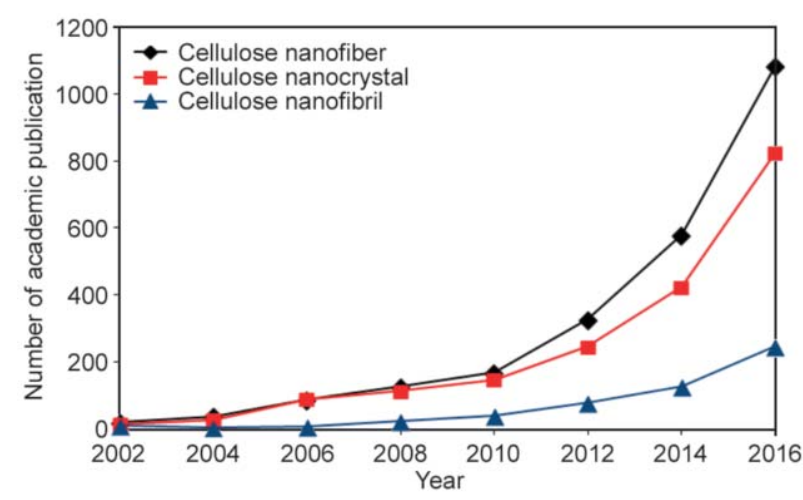

Figure 3. Number of academic publications with title containing different key words (data source: ScienceDirect).

and therefore it is crucial to standardize the terminology. TAPPI has completed a regularization of the terminology through developing the document Standard terms and their definition for cellulose nanomaterial (ISO/TS 20477) [35]. In this review, all terminology conforms to this proposed document.

As in many other fields, traditional cellulose materials have established a long and successful history in the pharmaceuticals. Readers are directed to the review by Kamel et al. [36] in this regard. Lately, the exploration of the applications of $\mathrm{CNs}$ in the pharmaceutical science and pharmacology has envisioned many key breakthroughs. The main objectives of this review are to examine and evaluate the most recent key advancements in applications of CNs in the broad fields of pharmaceutical science and pharmacology. In addition, the significant breakthroughs in the processing methods of CNs that are relevant to the applications are also thoroughly reviewed.

\section{Generating CNs}

A number of well-established methods have been used to generate CNs. The factors accounted for are source material, cost, convenience, scale, and purity.

\subsection{CNF}

Mechanical and chemical treatment on the cellulose fibers may produce the fibrillar or crystalline particles, through the process of defibrillation. Common techniques to defibrillate cellulose include refining, homogenizing, microfluidization, grinding, cryocrushing, and high intensity ultrasonication [12]. Mechanical fibrillation is the most widely used method to produce CNFs, including high pressure shearing [19] and grinding [37]. It is performed via a high pressure homogenizing process, involving a rotor and a stator disk where the raw materials (e.g., pulp) are forced through the gap between these two components [38]. The raw materials are thereby subject to high cyclic stresses, and the primary cell walls and outer secondary cell walls are detached. With the aid of high energy shearing, the cellulose fibers are split in the longitudinal direction into much thinner fibrils with the diameter falling in the nanometer range, resulting in CNFs. CNFs can be extracted from materials including sisal fibers [4], softwood sulphite pulp [38], banana petiole fibers [39], and wheat fiber [18]. From different source of the plant cells, the diameter of CNF may vary from tens to hundreds of nm [18].

\subsection{CNC}

The techniques to extract CNCs includes cryocrushing, chemomechanical, oxidation reaction, high pressure homogenization, steam explosion, disintegration using microwave, ionic liquid treatment, acid hydrolysis method, and enzymatic reaction [40, 41]. Among all of the listed methods, acid hydrolysis is most used, because of the convenience and low cost [42]. Owing to the susceptibility of the amorphous regions in the cellulose chains to acidity, acid treatment of cellulose or CNFs removes the amorphous sections, and therefore, the cellulose chains are cleaved transversely with only the highly crystalline regions retained, namely, CNCs. Commonly used source for CNCs include P. oceanica leaves (POL) and balls [43], Posidonia oceanic [44], curauá [3], kenaf bast [45], capim dourado [46], MCC [47]. In rare case, spherical CNCs were obtained via hydrolysis of a combination of sulfuric and hydrochloric acids under ultrasonication $[48,49]$. These CNCs with unusual morphology present an excellent thermal stability due to the smaller amount of sulfate groups.

\subsection{BC}

$\mathrm{BC}$ can be produced via the microbial fermentation process, by a few bacterial species, Gluconacetobacter hansenii ATCC 23769 [21] Gram-negative (including Gluconacetobacter, Agrobacterium, Pseudomonas, Rhodobacter, and Salmonella) and Grampositive (such as Sarcina ventriculi) species [50]. G. xylinus and $G$. hansenii are most extensively used to generate $\mathrm{BCs}$ because of the high productivity and the feasibility to use different carbon sources. The resulting material is normally less than $100 \mathrm{~nm}$ in width composed of aligned fibers that are $2 \sim 4 \mathrm{~nm}$ wide [18]. Some bacteria can produce amorphous 
cellulose as a biofilm component, such as from monomeric BcsA-B complexes [50].

\subsection{Other routes}

CNs are also extracted from marine animals, e.g., tunicates. CNs from tunicate and algae are expensive and are used as idealized particles for research purposes. CNs have been also produced from recycled paper products and other biomass residuals. The properties of CNC and CNF are largely affected by the source, i.e., the raw materials from which they are extracted [2]. For the properties of CNs extracted from different sources and methods, readers are directed to the reference [51]. While the pulp and paper, packaging, or, textile industries possess processing technology and lines that may directly or be modified to generate plant-based $\mathrm{CNs}$, it is most realistic to scale up the production at low cost and high throughput with this option.

\section{Processing}

The practical functionality under certain economic contexts, however, necessitates the cellulose-based materials to equal or surpass the performance and processability of the petroleum-based counterparts. This section discusses some recent advancements in $\mathrm{CN}$ processing methods that are related with the fields of pharmaceutical science and pharmacology.

\subsection{Surface modification}

Surface modification includes physical adsorption and chemical grafting. The ubiquitous hydroxyl groups lead to interfacial incompatibilities and low dispersibility of CNCs in hydrophobic media. In addition, water adsorption starts primarily at the hydroxyl groups, leading to the increased hydrophilicity and hygroscopicity with incorporated CNs. Esterification and silylation are often performed as hydrophobization process for CNs to improve water repellency and oil affinity. Peng et al. [52] presented an exhaustive study comparing $\mathrm{CNC}$ esterification methods attempting to control the hydrophobicity with the same source material. Acid anhydride had the best grafting efficiency for low molecular weight moieties with short aliphatic chains. For long chain aliphatic carbons, CDI was most viable due to more availability of grafting moieties in carboxylic acid form. In addition, the dispersibility of grafted CNCs in organic solvents was improved by using neverdried CNCs and keep CNCs wet with their washing solvents after reaction, thus increasing the solvency range of hydrophobic dispersibility. A solvent-free hydrophobization approach was reported by Abraham et al. [53] employing iodine as the catalyst, replacing hydroxyls with acetate ester resulting in highly hydrophobic and optically active CNCs. The degree of ester substitution 2.18 is much higher than previously reported values $0.01 \sim 1$. Targeting highly carboxylated CNCs, Sehaqui et al. [54] studied the esterification of cellulose with succinic anhydride, following high-shear mechanical disintegration with a microfluidizer. The carboxyl groups of $3.8 \mathrm{mmol} / \mathrm{g}$ were reported as the highest value from plant cellulose. The mechanism for this high carboxyl content was likely due to the large number of succinic anhydride molecules in the vicinity of cellulose surfaces while contracting many hydrogen bonds with them. The high carboxyl content enabled the strong repulsion of negative charges at the CNC surfaces, significantly facilitating CNCs isolation which necessitates less processing through the microfluidizer. The resulting $\mathrm{CNC}$ suspension is highly transparent and stable due the higher degree of dispersion.

Silane was reported to increase the hydrophobic surface area of CNCs [45]. Kargarzadeh et al. [55] used silane to surface-treat $\mathrm{CNCs}$ and the reinforced unsaturated polyester resin showed an improvement in strength and stiffness, and an exceptional increase in toughness by $96 \%$. Due to the less hydrophilicity after surface treatment, the water absorption was decreased with CNCs. While the silane surface-treatment reduced crystallinity of CNCs, it did not alter the size and aspect ratio.

The adsorption capacity of pristine cellulose fibers as drug carriers is quite mediocre, while surface modification to impart functional groups is commonly used to improve the adsorption performance [10]. Qing et al. [29] used cationic surfactant cetyltrimethyl ammoniumbromide to modify $\mathrm{CNCs}$, with the anionic sulfate groups on $\mathrm{CNCs}$, targeting controlled drug release especially for hydrophobic drug delivery. In addition, by grafting temperature-sensitive additives such as NIPAm ( $N$-isopropylacrylamide) to $\mathrm{CNs}$, the composites materials possess temperature controllable response, due to different swelling behavior of the cryogels. This temperature controllable response results in significant applicability in drug release [56]. Figure 4 describes the drug release profiles at different temperatures and NIPAm concentrations. AM-0, AM-1, AM-4 denote the cryogels with 
NIPAm at the concentrations of 0,6 , and $15 \%$ respectively. It can observed that the drug release profiles can be conveniently and precisely tuned via the
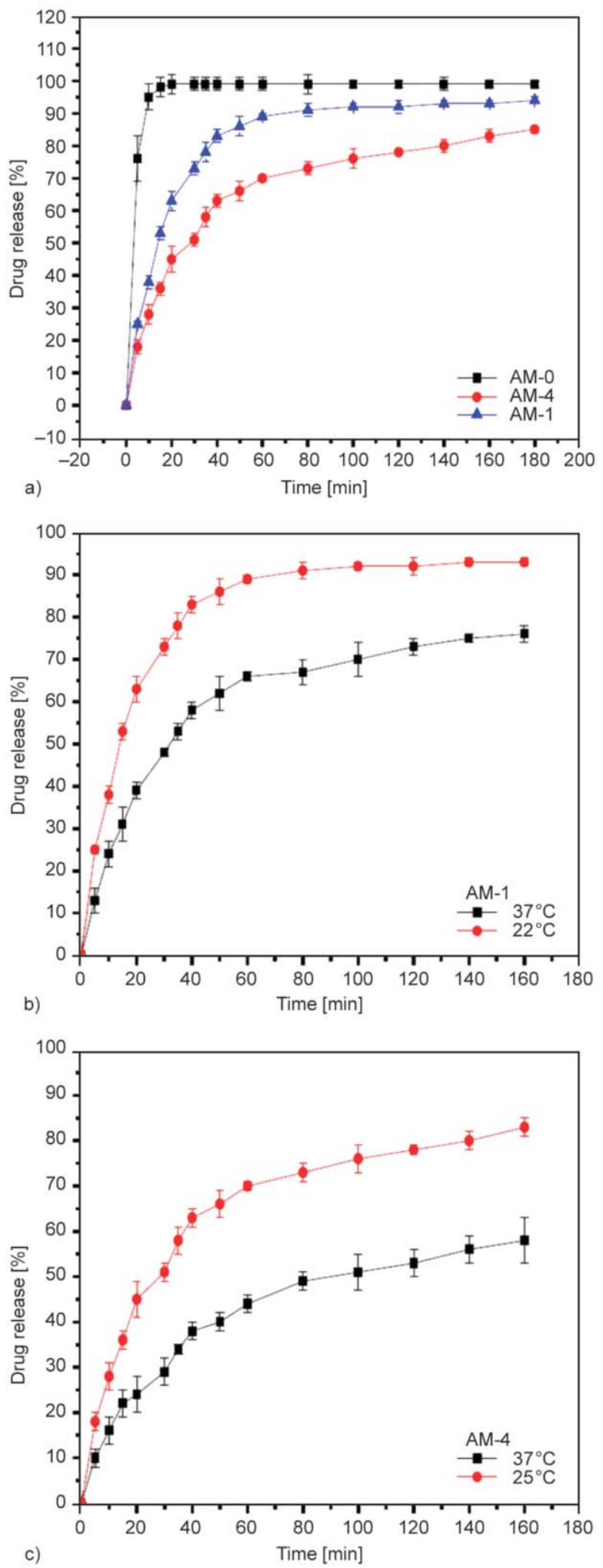

Figure 4. CNF microspheres and CNF-PNIPAm hybrid microspheres on 5-FU release at (a) different NIPAm concentrations; and (b, c) temperatures (figures reproduced from [56] with permission). concentration of the grafted NIPAm, ranging from an immediate release with 0 NIPAm to a substantially prolonged release with $15 \%$ NIPAm, that only about $40 \%$ of drug is released within the first 20 minutes.

\subsection{Dispersion and orientation}

The added concentration of CNs were normally subject to an upper limit, beyond which, the performance (mostly mechanical) reaches a plateau or even recedes [57-61]. This is a result of the difficulty to disperse the CNs at high volume fraction, because $\mathrm{CNs}$ are prone to agglomerate due to the interactions among the huge amount of hydroxyl groups [17]. Inadequate dispersion of the nano-fillers leads to local agglomeration, which act as stress concentrators, resulting in catastrophic failure under small deformations. In addition, the colloidal stability of CNCs in polar organic solvents is quite low without water addition. It is worth noting that when there are ions or introduced charges in the liquid medium, the agglomeration may be significantly promoted compared with an inert matrix [58].

It was reported that glycerol triacetate [62] and triethyl citrate [63] acted as a plasticizer to disperse the CNFs. TEMPO oxidation was also used to enhance CNF orientation in wet-spinning because of the elevated fibril aspect ratio and surface charge, leading to entanglement and osmotic repulsion between the fibrils. However an issue with TEMPO oxidation is the hygroscopicity caused by the higher specific surface area and surface charge. Therefore additional processing such as cross-linking or hydrophobization are needed to minimize or neutralize the negative influence. Wen et al. [26] reported a grafting method with polyacrylic acid in an attempt to improve the colloidal stability of CNCs. Commercially available surfactants were also reported to be effective to disperse CNCs, such as (Beycostat A B09 - CECCA S.A.), which was an acid phosphate ester of ethoxylatednonylphenol [44]. Iyer et al. [64] employed solid-state shear pulverization to prepare CNC-polyolefin composites with excellent dispersion and remarkable property enhancements, which is a single-step, solventless, continuous, and industrially scalable process.

Josefsson et al. [38] reported the degree of orientation of CNFs with the full width at half maximum (FWHM) as a quantitative method. Dispersion/aggregation can also be quantified via scattered light intensity [65]. The crossed polarizers may be used as 
a quick and qualitative indicator of the dispersion and orientation of CNCs [57].

\subsection{Crosslinking}

Crosslinking includes dynamic covalent reactions (chemical crosslinking) and noncovalent reactions (physical crosslinking). The inter-fiber hydrogen bonding between CNFs renders no necessity of crosslinking to produce an areogel. However, in aqueous condition, $\mathrm{CNF}$ aerogels present a low structural stability due to the compromised inter-fiber hydrogen bonding and mechanical entanglement [19]. Covalent crosslinking is a common method to enhance structural stability. Ethylenediamine and hexamethylenediamine were used as crosslinkers to form reversible CNF hydrogels via the covalent crosslinking of aldehyde groups on the CNFs [66]. It was also verified that by varying the concentration and length of the crosslinkers, the elastic modulus of hydrogel can be conveniently controlled. Another recent approach was to use maleic acid with hypohosphite to achieve crosslinking in aqueous medium [19]. Masruchin et al. [67] used trivalent, divalent, and monovalent cations to induce ionic crosslinking between TEMPOmediated CNFs. With increasing amount of $\mathrm{Al}^{3+}$, the mechanical performance of the resulting hydrogels was improved. A green crosslinking resin, polyamide Epichlorohydrin (Polycup), was reported to be able to control the swelling and water absorption [68]. Zhang et al. [69] crosslinked the TEMPO-mediated CNFs with poly (sodium acrylate), resulting in a high volume expansion of about 27 times $\mathrm{v} / \mathrm{v}$. The self-recovery capabilities are chemically incorporated into the polymeric architectures via the reversible bonds (crosslinks/reactions). Due to the much smaller lengths and high rigidity, crosslinking is not so commonly used for CNCs as CNFs. A typical example was to use hydrazide and aldehyde surface functionalization, leading to ultralightweight $\left(5.6 \mathrm{mg} / \mathrm{cm}^{3}\right)$ and highly porous $(99.6 \%)$ aerogels [70].

\section{Applications}

In this section, the utilities and functionalities of $\mathrm{CNs}$ in the fields of pharmaceutical science and pharmacology are discussed. Because of the relatively low rigidity of CNFs as a result of the alternating crystallinity, they are more often used in biomedical applications compared with CNCs [71].

\subsection{Oral administration}

There has been a fleetly increasing interest in using areogels/hydrogels to host drugs, enzymes, and proteins. The loading may be achieved through the solgel process before the formation of gel, or adding the API into the generated aerogel. CN-based aerogels possess the biodegradability and biocompatibility that traditional silica aerogels lack, while the drug loading of pristine cellulose is reported to be fairly low [11]. The open and porous structure of CNF areogels/hydrogels can potentially carry and release drugs. A controlled drug release can be established by fine-tuning the internal structures of the hydrogels. As a drug vehicle, hydrogel serves as a protective barrier from degradation (e.g., enzymes) and regulates the release of the API. The swelling of the polymer chains leads to enlargement of pores that facilitate drug release into the dissolution medium. Laurén et al. [32] reported the use of CNF hydrogels for controlled release or local delivery of large APIs. Zhao et al. [11] reported the polyethylenimine-grafted CNF aerogels as drug delivery vehicles for sodium salicylate. Figure 5 provides a production cycle of the aerogel. This work demonstrated a high drug loading of up to $287 \mathrm{mg} / \mathrm{g}$ at $\mathrm{pH}$ of 3 . In addition, the drug release test shows a sustained release behavior. It is noteworthy that the release profile was largely influenced by $\mathrm{pH}$ and temperature, suggesting a great potential of controlled release. Another case study of theophylline-loaded CNF hydrogels reported slow and low total drug release, because of the compact structures of the hydrogels [67].

Jackson et al. [72] used CNC as a drug delivery excipient for ionizable water soluble drugs, tetratcycline and doxorubicin, and surface modified CNC for nonionized hydrophobic compounds, docetaxel, paclitaxel, and etoposide. This study showed an excellent binding capacity of $\mathrm{CNCs}$, which appeared due to their high surface area with the negative charges. The cetyltrimethylammonium bromide modified CNCs were reported to output a sustained release over one day for hydrophobic drugs such as luteolin and luteoloside [29]. It is reported that a combination of CNC, alginate, and pectin, as a suitable excipient, preserve the high viability of probiotic bacterium, and the performance is much better than the three components alone [73]. The proposed mechanism is the hydrogel around the probiotic cells act as the protective layer 

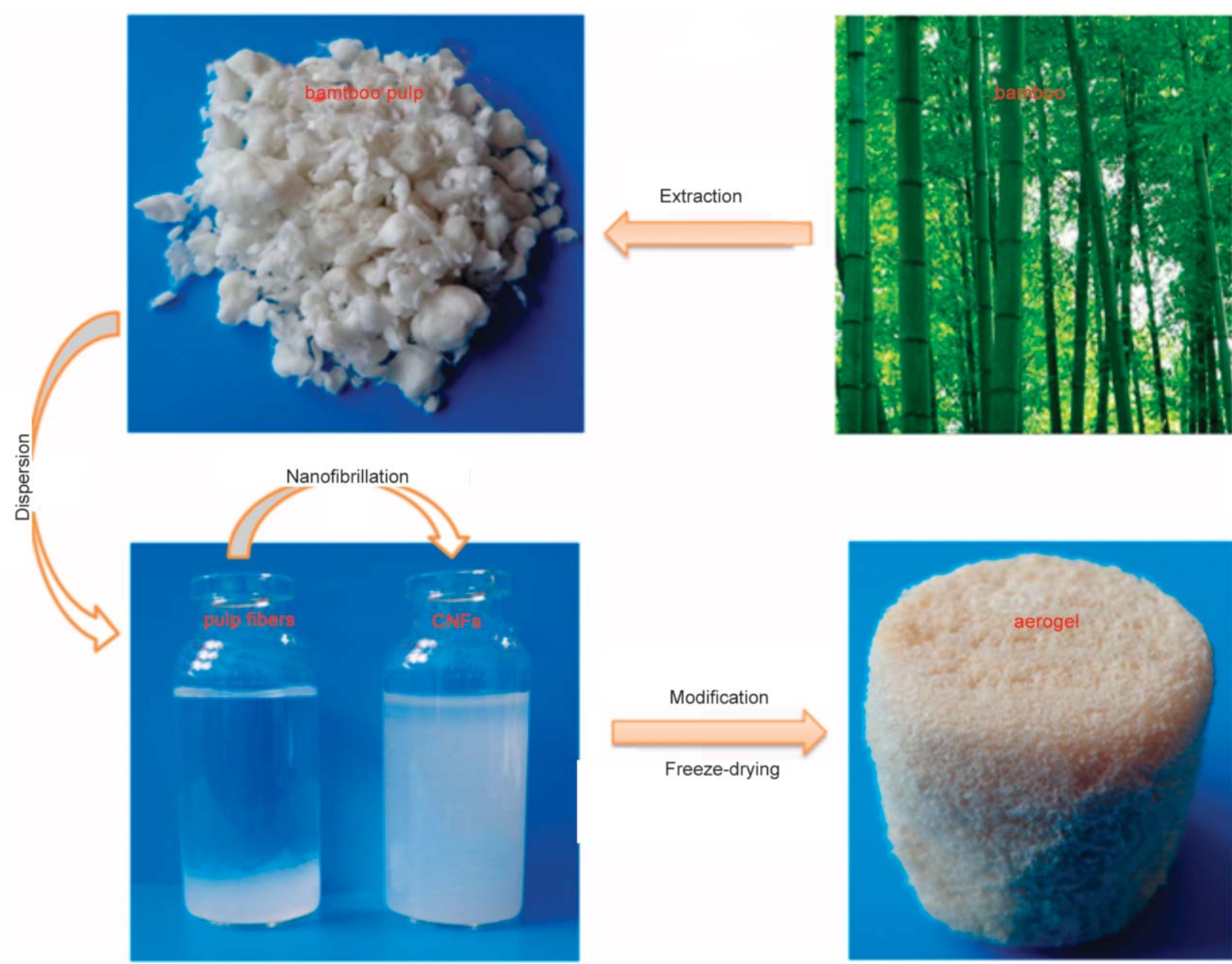

Figure 5. Production cycle of the aerogel (figure reproduced from [11] with permission).

from the acidic gastric fluid permeation. An additional benefit is the storage preservation at both 25 and $4{ }^{\circ} \mathrm{C}$, with insignificant reduction in viability after 42 days.

\subsection{Topical administration}

The pristine CNFs can induce active immune tolerance, enabling treatment of exaggerated inflammatory conditions threatening to destroy host tissue and support of wound healing [71]. In addition, oxidized CNF gels could act as $\mathrm{pH}$ responsive structures, which may have applications in dressings for chronic wounds. Rees et al. [74] pretreated CNFs with a combination of carboxymethylation and periodate oxidation. The CNF gel was successfully extruded via a Bioplotter, involving air pressure as the driving force to form a designated 3D pattern. In addition, this printed structure has an inhibitive effect on bacterial growth, which supports its medical application, such as wound dressing. The CNCs were reported to act as an excellent topical drug delivery vehicle for hydroquinone [75]. The complex was conveniently prepared by mixing CNCs with hydroquinone in water to form a suspension. It was found that the API was successfully bound onto the surface of CNCs in high weight ratios at $\sim 80 \%$. The release study showed that $\sim 40 \%$ of hydroquinone was released within 1 hour and $\sim 80 \%$ in 4 hours. Due to the antioxidant effect of CNCs, the complex presented a significantly higher stability compared to hydroquinone alone, which is practically significant in improving the storage life to drugs. Lazarini et al. [21] generated a high density entangled $\mathrm{BC}$ network which showed the capacity of sustained release of antibiotics. This is highly favorable in wound dressings such as the treatment of skin infections.

\subsection{Tissue scaffolds}

As a 3D-network soft material with tunable structures and physicochemical properties, $\mathrm{CN}$ hydrogel' water-retention feature and network structure can be paralleled to those of the extracellular matrix. It exhibits a great potential for use in tissue scaffolds, if the elastic modulus and strength can be precisely 
controlled [66]. The conventional polymer hydrogels suffer from brittleness under stress, which may be due to the inhomogeneously crosslinked structures, insufficient interactions between chains, and lack of efficient energy dissipation. In the text above, the crosslinking was discussed to fine-tune the $\mathrm{CN}$ hydrogel structures to be suitable for a variety of applications. When the spaces between individual CNFs are increased, the number of hydrogen bonds decreases. Yang and Han [76] fabricated CNC porous network reinforced polyacrylamide (PAAm) hydrogel with hydrophilic crosslinker PEGDA575. The resulting hydrogel exhibited a superior performance, i.e., a tensile strength of $181 \mathrm{kPa}$ and compressive strength of $1.01 \mathrm{MPa}$. In addition, the recovery was up to $70 \%$ after 8 loading-unloading cycles. Based on Figure 6, the rigidity of the hydrogel is significantly improved from the pristine PAAm. The enhanced mechanical properties originated from the synergistic effects of the CNC skeleton and the elastic PAAm network, namely the sacrificial hydrogen bonds between CNC and PAAm and the elastic covalently crosslinked PAAm chains, providing an efficient energy dissipation. The high strength is greatly appreciated in scaffolds for tissue engineering.

\subsection{Antibacterial}

CNF film deposited with Ag nanoparticles were reported to show antibacterial effects for Escherichia coli (E. coli, Gram-negative) and Staphylococcus aureus (S. aureus, Gram-positive) [6]. The immobilization the Ag nanoparticles onto CNFs was via covalent binding by mediation of dendrimer, which is a facile approach and may be generalized to any combination of metallic nanoparticles. Other than $\mathrm{Au}$ and $\mathrm{Ag}$, less costive $\mathrm{Cu}$ nanoparticles have also been incorporated into TEMPO-mediated CNFs to form an antimicrobial composite for controlled release [77]. The CNFs, as a template, were demonstrated to be able to regulate $\mathrm{Cu}$ release and provide a long term antimicrobial performance due to barrier capability of CNFs of copper oxidation and dissolution and reserve $\mathrm{Cu}$ nanoparticles from immediate release. Jin et al. [78] fabricated an amphiphobic cellulose-based material which effectively inhibits the adhesion of bacteria such as lysogenic E. coli. The first step is to etch the surface with alkaline solution to enhance the surface roughness, followed by depositing ultrathin titania onto the CNFs by a facile surface sol-gel approach. With a $1 \mathrm{H}, 1 \mathrm{H}, 2 \mathrm{H}, 2 \mathrm{H}$-perfluorooctyl trimethoxysilane monolayer self-assembled onto $\mathrm{CNFs}$,

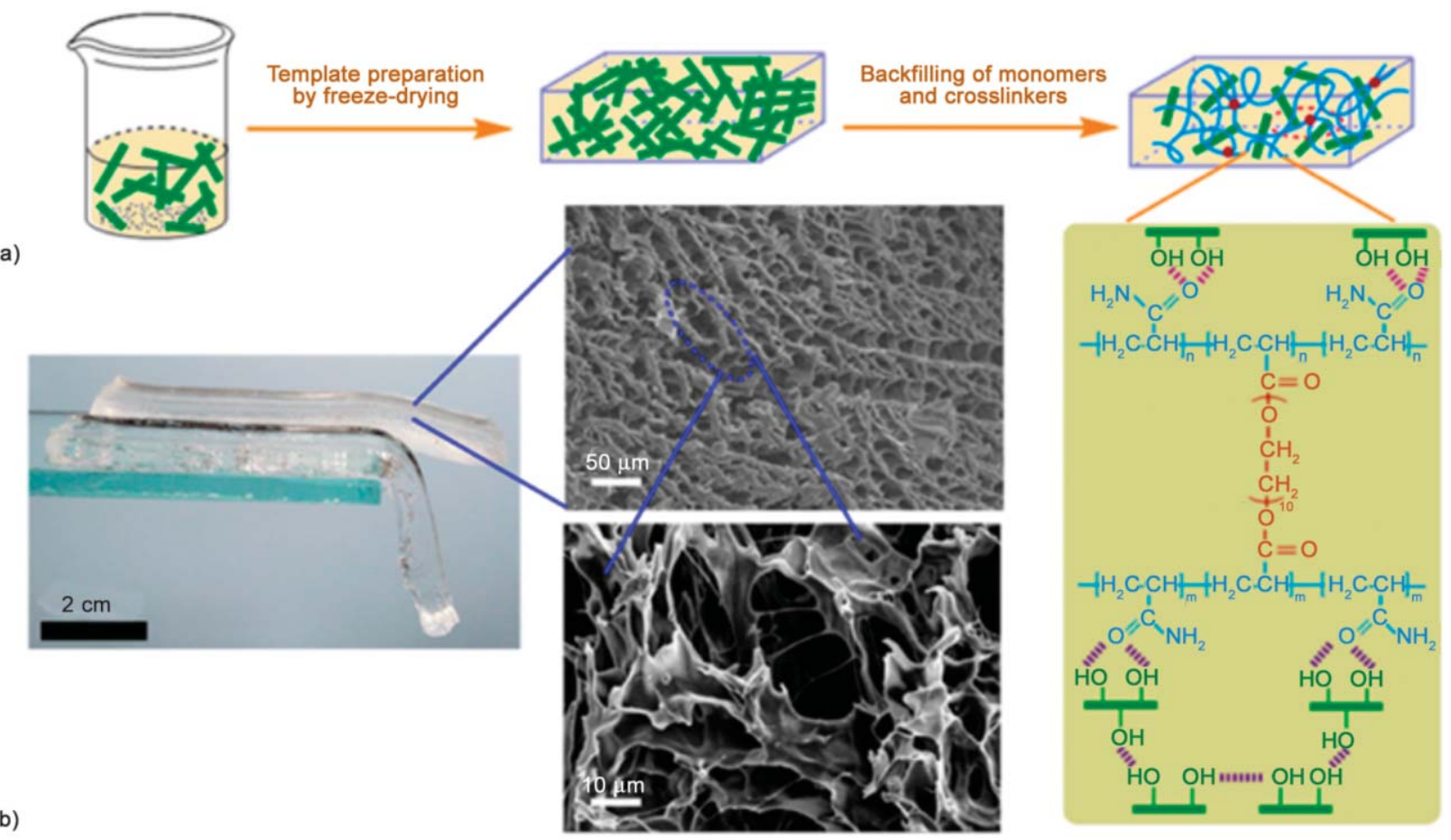

Figure 6. (a) Scheme of preparation procedure for CNC skeleton reinforced hydrogels. (b) The skeleton reinforced CNC 0.5 hydrogels become white, opaque, and rigid relative to pristine PAAm hydrogels. Cross-sectional SEM images of the freeze-dried $\mathrm{CNC} 0.5$ hydrogels exhibit an interconnected comb-like network structure (figures from [76] with permission). 


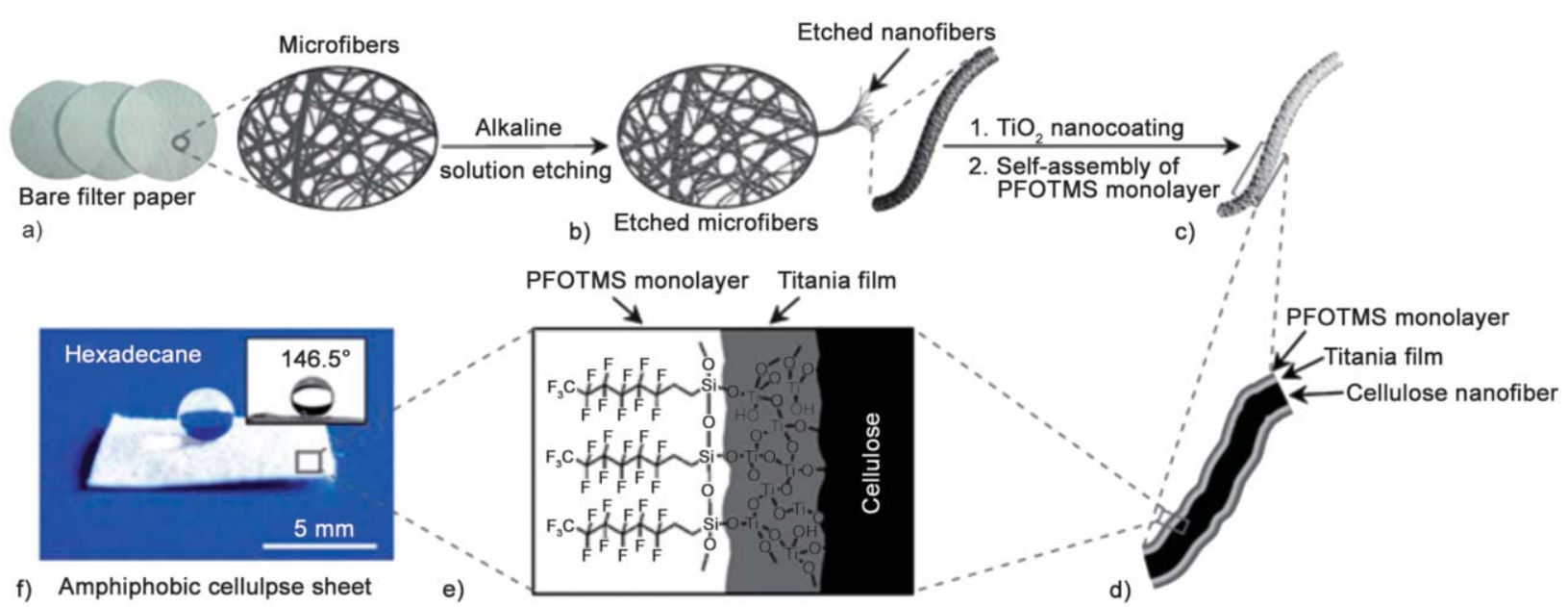

Figure 7. Schematic illustration of the fabrication process of the amphiphobic cellulose sheet (figure from [78] with permission). a) Cellulose microfibers of the commercial filter paper; b) rougher cellulose fibers of the filter paper resulting from the alkaline solution etching; c) cellulose nanofiber of the etched filter paper deposited with titania-PFOTMS composite ultrathin films; d) and e) structure of the titania-PFOTMS ultrathin film modified cellulose nanofiber, PFOTMS molecules are covalently bonded onto the titania film surface forming a monolayer and f) the resulting amphiphobic cellulose sheet shows a contact angle of $146.5^{\circ}$ for hexadecane.

the surface demonstrated both superhydrophobicity and high oleophobicity. As presented in Figure 7, the final product exhibits superhydrophobicity with a contact angle of $146.5^{\circ}$, effectively inhibits the adhesion of bacteria such as lysogenic E. coli.

\section{Future prospects and challenges}

The use of CNs in pharmaceutical science and pharmacology has been experiencing a huge leap in last few years. As one may see common statements of cellulose materials regarding their environmentally friendliness and nontoxicity [11], it is questionable to treat the CNCs and CNFs as $100 \%$ nontoxic substances in research, manufacturing, and applications, considering the toxicity of nanoparticles [79]. The cytotoxicity of various CNs has been investigated, confirming the noncytotoxic against a series of cell lines; and also CNFs do not seem to induce cytotoxicity and inflammation. However up until now there was only limited toxicity study on CNC [80].

While the biodegradability of cellulose has been advocated as one of its most prominent advantages in many applications, concerns arise when cellulose interact with bacteria, resulting in an expedited degradation process, and therefore compromising the functionality. In cases where CNs are trapped or intimately contained in matrices, such as polymer, the degradation may be insignificant, while when they are exposed the environment, (e.g., substrate for solar energy conversion), the process can be detrimental. Focused investigations, therefore, are required to con- firm that the biodegradability does not pose an adverse effect in the usage life of the applications.

Large scale production of CNs remains challenging. There are only limited facilities, e.g., US Forest Products Laboratory (Madison Wisconsin) that may deliver large batch throughputs. Currently the costs of CNs are comparable with nanomaterials such as carbon nanotubes. To further lower the costs of $\mathrm{CNs}$ and make them more competitive, advances in processing technology are necessitated to increase the throughput, improve the yield, and decrease energy consumption. In addition, although quite a few sources have been demonstrated to be viable to extract $\mathrm{CNs}$, continuous research will further explore more possibilities to generate the materials at even lower price, e.g., using recycled paper or cotton.

Since it demands a high cost to store and transfer CNs when they are in a form of suspension (most often aqueous), dried materials are much cost-effective. In addition, for a variety of practical applications when water (or other solvents) is not involved, evaporation is necessary prior to use. Drying, however, leads to common concerns of the irreversibility of $\mathrm{CN}$ agglomeration [12].

The last but not the least, an interdisciplinary collaboration is urgent to explore the possibilities from fundamental science to applications. The efforts are not limited within the researchers in the fields of pharmaceutical science and pharmacology, while the expertise from a wide scope of fields, including materials science, chemical engineering, and industrial 
engineering, are necessary to productively deliver reliable results. The leveraging of the knowledge bases from different areas have resulted in a few successful collaborations [81].

\section{Conclusions}

This review discusses the most recent key developments of using CNs in the fields of pharmaceutical science and pharmacology. The advantages of the $\mathrm{CNs}$ over other nanomaterials are remarkable, that they are friendly to environment and human beings; the vast abundance and recyclability make them easily available and unexpendable. In addition, the large amount of hydroxyl groups on the surface make the CNs modifiable and tunable, which are extremely important for the processing in the pharmaceutical science and pharmacology. The applications of CNs have been found in a variety of fields. As CNs experience an aggressive exploration, prospectives and challenges co-exist, while we foresee another round of trends of nanomaterials going greener and more applicable.

\section{References}

[1] Wang W., Sabo R. C., Mozuch M. D., Kersten P., Zhu J. Y., Jin Y.: Physical and mechanical properties of cellulose nanofibril films from bleached eucalyptus pulp by endoglucanase treatment and microfluidization. Journal of Polymers and the Environment, 23, 551-558 (2015).

https://doi.org/10.1007/s10924-015-0726-7

[2] Zhang L., Liu Z., Cui G., Chen L.: Biomass-derived materials for electrochemical energy storages. Progress in Polymer Science, 43, 136-164 (2015).

https://doi.org/10.1016/j.progpolymsci.2014.09.003

[3] de Castro D. O., Frollini E., Ruvolo-Filho A., Dufresne A.: 'Green polyethylene' and curauá cellulose nanocrystal based nanocomposites: Effect of vegetable oils as coupling agent and processing technique. Journal of Polymer Science Part B: Polymer Physics, 53, 1010 1019 (2015).

https://doi.org/10.1002/polb.23729

[4] Deepa B., Abraham E., Pothan L. A., Cordeiro N., Faria M., Thomas S.: Biodegradable nanocomposite films based on sodium alginate and cellulose nanofibrils. Materials, 9, 1-11 (2016).

https://doi.org/10.3390/ma9010050

[5] Wang S., Lu A., Zhang L.: Recent advances in regenerated cellulose materials. Progress in Polymer Science, 53, 169-206 (2016). https://doi.org/10.1016/j.progpolymsci.2015.07.003
[6] Ramarajua B., Imae T., Destaye A. G.: Ag nanoparticle-immobilized cellulose nanofibril films for environmental conservation. Applied Catalysis A: General, 492, 184-189 (2015). https://doi.org/10.1016/j.apcata.2014.12.045

[7] Ma H., Burger C., Hsiao B. S., Chu B.: Fabrication and characterization of cellulose nanofiber based thin-film nanofibrous composite membranes. Journal of Membrane Science, 454, 272-282 (2014). https://doi.org/10.1016/j.memsci.2013.11.055

[8] Xia Y., Wang Y., Fang H. H. P., Jin T., Zhong H., Zhang T.: Thermophilic microbial cellulose decomposition and methanogenesis pathways recharacterized by metatranscriptomic and metagenomic analysis. Scientific Reports, 4, 1-9 (2014). https://doi.org/10.1038/srep06708

[9] Gregorczyk K., Knez M.: Hybrid nanomaterials through molecular and atomic layer deposition: Top down, bottom up, and in-between approaches to new materials. Progress in Materials Science, 75, 1-37 (2016). https://doi.org/10.1016/j.pmatsci.2015.06.004

[10] Zhang F., Wu W., Sharma S., Tong G., Deng Y.: Synthesis of cyclodextrin-functionalized cellulose nanofibril aerogel as a highly effective adsorbent for phenol pollutant removal. BioResources, 10, 7555-7568 (2015). https://doi.org/10.15376/biores. 10.4.7555-7568

[11] Zhao J., Lu C., He X., Zhang X., Zhang W., Zhang X.: Polyethylenimine-grafted cellulose nanofibril aerogels as versatile vehicles for drug delivery. ACS Applied Materials and Interfaces, 7, 2607-2615 (2015). https://doi.org/10.1021/am507601m

[12] Khalil H. P. S. A., Davoudpour Y., Islam M. N., Mustapha A., Sudesh K., Dungani R., Jawaid M.: Production and modification of nanofibrillated cellulose using various mechanical processes: A review. Carbohydrate Polymers, 99, 649-665 (2014).

https://doi.org/10.1016/j.carbpol.2013.08.069

[13] Ching Y. C., Ali M. E., Abdullah L. C., Choo K. W., Kuan Y. C., Julaihi S. J., Chuah C. H., Liou N-S.: Rheological properties of cellulose nanocrystal-embedded polymer composites: A review. Cellulose, 23, 10111030 (2016).

https://doi.org/10.1007/s10570-016-0868-3

[14] Maase M., Massonne K., Uerdingen E., Vagt U.: Solutions of cellulose in ionic liquids. Aldrich ChemFiles, 6, 3-3 (2006).

[15] National Renewable Energy Laboratory: Technology roadmap for plant/crop-based renewable resources 2020. 1-44 (2012).

[16] Alexandrescu L., Syverud K., Nicosia A., Santachiara G., Fabrizi A., Belosi F.: Airborne nanoparticles filtration by means of cellulose nanofibril based materials. Journal of Biomaterials and Nanobiotechnology, 7, 2936 (2016). https://doi.org/10.4236/jbnb.2016.71004 
[17] Mariano M., Kissi N. E., Dufresne A.: Cellulose nanocrystals and related nanocomposites: Review of some properties and challenges. Journal of Polymer Science Part B: Polymer Physics, 52, 791-806 (2014). https://doi.org/10.1002/polb.23490

[18] Habibi Y.: Key advances in the chemical modification of nanocelluloses. Chemical Society Reviews, 43, 1519-1542 (2014).

https://doi.org/10.1039/C3CS60204D

[19] Kim C. H., Youn H. J., Lee H. L.: Preparation of crosslinked cellulose nanofibril aerogel with water absorbency and shape recovery. Cellulose, 22, 3715-3724 (2015). https://doi.org/10.1007/s10570-015-0745-5

[20] Usov I., Nyström G., Adamcik J., Handschin S., Schütz C., Fall A., Bergström L., Mezzenga R.: Understanding nanocellulose chirality and structure-properties relationship at the single fibril level. Nature Communications, 6, 7564/1-7564/11 (2015).

https://doi.org/10.1038/ncomms8564

[21] Lazarini S. C., de Aquino R., Amaral A. C., Corbi F. C. A., Corbi P. P., Barud H. S.: Characterization of bilayer bacterial cellulose membranes with different fiber densities: A promising system for controlled release of the antibiotic ceftriaxone. Cellulose, 23, 737-748 (2016). https://doi.org/10.1007/s10570-015-0843-4

[22] Siqueira G., Kokkinis D., Libanori R., Hausmann M. K., Gladman A. S., Neels A.: Cellulose nanocrystal inks for 3D printing of textured cellular architectures. Advanced Functional Materials, 27, 1604619/1-1604619/10 (2017).

https://doi.org/10.1002/adfm.201604619

[23] Mohammadi P., Toivonen M. S., Ikkala O., Wagermaier W., Linder M. B.: Aligning cellulose nanofibril dispersions for tougher fibers. Scientific Reports, 7, 11860/111860/10 (2017).

https://doi.org/10.1038/s41598-017-12107-x

[24] Rahman M. M., Netravali A. N.: Aligned bacterial cellulose arrays as 'green' nanofibers for composite materials. ACS Macro Letters, 5, 1070-1074 (2016). https://doi.org/10.1021/acsmacrolett.6b00621

[25] Cao Y., Verian K. P.: A VEDA simulation on cement paste: Using dynamic atomic force microscopy to characterize cellulose nanocrystal distribution. MRS Communications, 7, 672-676 (2017). https://doi.org/10.1557/mrc.2017.57

[26] Wen Y., An X., Zhu X., Cheng X., Dong C., Cheng D., Nasrallah J. E.: Improving the colloidal stability of cellulose nano-crystals by surface chemical grafting with polyacrylic acid. Journal of Bioresources and Bioproducts, 1, 114-119 (2016). https://doi.org/10.21967/jbb.v1i3.6

[27] Anwar B., Rosyid N. H., Effendi D. B., Nandiyanto A. B. D., Mudzakir A., Hidayat T.: Isolation of bacterial cellulose nanocrystalline from pineapple peel waste: Optimization of acid concentration in the hydrolysis method. AIP Conference Proceedings, 1708, 040001/1040001/4 (2016).

https://doi.org/10.1063/1.4941151
[28] Oun A. A., Rhim J-W.: Preparation and characterization of sodium carboxymethyl cellulose/cotton linter cellulose nanofibril composite films. Carbohydrate Polymers, 127, 101-109 (2015). https://doi.org/10.1016/j.carbpol.2015.03.073

[29] Qing W., Wang Y., Wang Y., Zhao D., Liu X., Zhu J.: The modified nanocrystalline cellulose for hydrophobic drug delivery. Applied Surface Science, 366, 404--409 (2016).

https://doi.org/10.1016/j.apsusc.2016.01.133

[30] Mohammadkazemi F., Doosthoseini K., Ganjian E., Azin M.: Manufacturing of bacterial nano-cellulose reinforced fiber-cement composites. Construction and Building Materials, 101, 958-964 (2015). https://doi.org/10.1016/j.conbuildmat.2015.10.093

[31] Lam E., Male K. B., Chong J. H., Leung A. C. W., Luong J. H. T.: Applications of functionalized and nanoparticle-modified nanocrystalline cellulose. Trends in Biotechnology, 30, 283-290 (2012). https://doi.org/10.1016/j.tibtech.2012.02.001

[32] Laurén P., Lou Y-R., Raki M., Urtti A., Bergström K., Yliperttula M.: Technetium-99m-labeled nanofibrillar cellulose hydrogel for in vivo drug release. European Journal of Pharmaceutical Sciences, 65, 79-88 (2014). https://doi.org/10.1016/j.ejps.2014.09.013

[33] Sani N., Wang X., Granberg H., Ersman P. A., Crispin X., Dyreklev P., Engquist I., Gustafsson G., Berggren M.: Flexible lamination-fabricated ultra-high frequency diodes based on self-supporting semiconducting composite film of silicon micro-particles and nano-fibrillated cellulose. Scientific Reports, 6, 28921/1-28921/8 (2016). https://doi.org/10.1038/srep28921

[34] Ji S., Hyun B. G., Kim K., Lee S. Y., Kim S-H., Kim JY., Song M. H., Park J-U.: Photo-patternable and transparent films using cellulose nanofibers for stretchable origami electronics. NPG Asia Materials, 8, e299/1e299/9 (2016). https://doi.org/10.1038/am.2016.113

[35] ISO/TS 20477: Nanotechnologies - Standard terms and their definition for cellulose nanomaterial. (2017).

[36] Kamel S., Ali N., Jahangir K., Shah S. M., El-Gendy A. A.: Pharmaceutical significance of cellulose: A review. Express Polymer Letters, 2, 758-778 (2008). https://doi.org/10.3144/expresspolymlett.2008.90

[37] Sim K., Ryu J., Youn H. J.: Structural characteristics of nanofibrillated cellulose mats: Effect of preparation conditions. Fibers and Polymers, 16, 294-301 (2015). https://doi.org/10.1007/s12221-015-0294-4

[38] Josefsson G., Ahvenainen P., Mushi N. E., Gamstedt E. K.: Fibril orientation redistribution induced by stretching of cellulose nanofibril hydrogels. Journal of Applied Physics, 117, 214311/1-214311/5 (2015). https://doi.org/10.1063/1.4922038 
[39] Xu C., Wang G., Xing C., Matuana L. M., Zhou H.: Effect of graphene oxide treatment on the properties of cellulose nanofibril films made of banana petiole fibers. BioResources, 10, 2809-2822 (2015).

https://doi.org/10.15376/biores.10.2.2809-2822

[40] Khalil H. P. S. A., Bhat A. H., Yusra A. F. I.: Green composites from sustainable cellulose nanofibrils: A review. Carbohydrate Polymers, 87, 963-979 (2012).

https://doi.org/10.1016/j.carbpol.2011.08.078

[41] George J., Ramana K. V., Bawa A. S., Siddaramaiah: Bacterial cellulose nanocrystals exhibiting high thermal stability and their polymer nanocomposites. International Journal of Biological Macromolecules, 48, 50 57 (2011).

https://doi.org/10.1016/j.ijbiomac.2010.09.013

[42] Sadeghifar H., Filpponen I., Clarke S. P., Brougham D. F., Argyropoulos D. S.: Production of cellulose nanocrystals using hydrobromic acid and click reactions on their surface. Journal of Materials Science, 46, 7344 7355 (2011)

https://doi.org/10.1007/s10853-011-5696-0

[43] Bettaieb F., Khiari R., Dufresne A., Mhenni M. F., Belgacem M. N.: Mechanical and thermal properties of Posidonia oceanica cellulose nanocrystal reinforced polymer. Carbohydrate Polymers, 123, 99-104 (2015). https://doi.org/10.1016/j.carbpol.2015.01.026

[44] Fortunati E., Luzi F., Puglia D., Petrucci R., Kenny J. M., Torre L.: Processing of PLA nanocomposites with cellulose nanocrystals extracted from posidonia oceanica waste: Innovative reuse of coastal plant. Industrial Crops and Products, 67, 439-447 (2015). https://doi.org/10.1016/j.indcrop.2015.01.075

[45] Kargarzadeh H., Sheltami R. M., Ahmad I., Abdullah I., Dufresne A.: Cellulose nanocrystal reinforced liquid natural rubber toughened unsaturated polyester: Effects of filler content and surface treatment on its morphological, thermal, mechanical, and viscoelastic properties. Polymer, 71, 51-59 (2015).

https://doi.org/10.1016/j.polymer.2015.06.045

[46] Mariano M., El Kissi N., Dufresne A.: Structural reorganization of $\mathrm{CNC}$ in injection-molded $\mathrm{CNC} / \mathrm{PBAT}$ materials under thermal annealing. Langmuir, 32, 10093 10103 (2016).

https://doi.org/10.1021/acs.langmuir.6b03220

[47] Espino-Pérez E., Bras J., Almeida G., Relkin P., Belgacem N., Plessis C., Domenek S: Cellulose nanocrystal surface functionalization for the controlled sorption of water and organic vapours. Cellulose, 23, 2955-2970 (2016). https://doi.org/10.1007/s10570-016-0994-y

[48] Wang N., Ding E., Cheng R.: Preparation and liquid crystalline properties of spherical cellulose nanocrystals. Langmuir, 24, 5-8 (2008). https://doi.org/10.1021/la702923w

[49] Wang N., Ding E., Cheng R.: Thermal degradation behaviors of spherical cellulose nanocrystals with sulfate groups. Polymer, 48, 3486-3493 (2007).

https://doi.org/10.1016/j.polymer.2007.03.062
[50] Basu S., Omadjela O., Gaddes D., Tadigadapa S., Zimmer J., Catchmark J. M.: Cellulose microfibril formation by surface-tethered cellulose synthase enzymes. ACS Nano, 10, 1896-1907 (2016). https://doi.org/10.1021/acsnano.5b05648

[51] Sacui I. A., Nieuwendaal R. C., Burnett D. J., Stranick S. J., Jorfi M., Weder C., Foster E. J., Olsson R. T., Gilman J. W.: Comparison of the properties of cellulose nanocrystals and cellulose nanofibrils isolated from bacteria, tunicate, and wood processed using acid, enzymatic, mechanical, and oxidative methods. ACS Applied Materials and Interfaces, 6, 6127-6138 (2014). https://doi.org/10.1021/am500359f

[52] Peng S. X., Chang H., Kumar S., Moon R. J., Youngblood J.: A comparative guide to controlled hydrophobization of cellulose nanocrystals via surface esterification. Cellulose, 23, 1825-1846 (2016). https://doi.org/10.1007/s10570-016-0912-3

[53] Abraham E., Kam D., Nevo Y., Slattegard R., Rivkin A., Lapidot S., Shoseyov O.: Highly modified cellulose nanocrystals and formation of epoxy-nanocrystalline cellulose (CNC) nanocomposites. ACS Applied Materials and Interfaces, 8, 28086-28095 (2016).

https://doi.org/10.1021/acsami.6b09852

[54] Sehaqui H., Kulasinski K., Pfenninger N., Zimmermann T., Tingaut P.: Highly carboxylated cellulose nanofibers via succinic anhydride esterification of wheat fibers and facile mechanical disintegration. Biomacromolecules, 18, 242-248 (2017).

https://doi.org/10.1021/acs.biomac.6b01548

[55] Kargarzadeh H., Sheltami R. M., Ahmad I., Abdullah I., Dufresne A.: Cellulose nanocrystal: A promising toughening agent for unsaturated polyester nanocomposite. Polymer, 56, 346-357 (2015). https://doi.org/10.1016/j.polymer.2014.11.054

[56] Zhang F., Wu W., Zhang X., Meng X., Tong G., Deng Y.: Temperature-sensitive poly-NIPAm modified cellulose nanofibril cryogel microspheres for controlled drug release. Cellulose, 23, 415-425 (2016). https://doi.org/10.1007/s10570-015-0799-4

[57] Chen S., Schueneman G., Pipes R. B., Youngblood J., Moon R. J.: Effects of crystal orientation on cellulose nanocrystals-cellulose acetate nanocomposite fibers prepared by dry spinning. Biomacromolecules, 15, 38273835 (2014). https://doi.org/10.1021/bm501161v

[58] Cao Y., Zavattieri P., Youngblood J., Moon R., Weiss J.: The relationship between cellulose nanocrystal dispersion and strength. Construction and Building Materials, 119, 71-79 (2016). https://doi.org/10.1016/j.conbuildmat.2016.03.077

[59] Cao Y., Tian N., Bahr D., Zavattieri P. D., Youngblood J., Moon R. J., Weiss J.: The influence of cellulose nanocrystals on the microstructure of cement paste. Cement and Concrete Composites, 76, 164-173 (2016). https://doi.org/10.1016/j.cemconcomp.2016.09.008 
[60] Cao Y., Zavaterri P., Youngblood J., Moon R., Weiss J.: The influence of cellulose nanocrystal additions on the performance of cement paste. Cement and Concrete Composites, 56, 73-83 (2015).

https://doi.org/10.1016/j.cemconcomp.2014.11.008

[61] Cao Y., Weiss J., Youngblood J., Moon R., Zavattieri P.: Performance-enhanced cementitious materials by cellulose nanocrystal additions. in 'Production and applications of cellulose nanomaterials' (eds.: Postek M. T., Moon R. J., Rudie A., Bilodeau M.) TAPPI Press, Peachtree Corners, 135-136 (2013).

[62] Herrera N., Mathew A. P., Oksman K.: Plasticized polylactic acid/cellulose nanocomposites prepared using melt-extrusion and liquid feeding: Mechanical, thermal and optical properties. Composites Science and Technology, 106, 149-155 (2015).

https://doi.org/10.1016/j.compscitech.2014.11.012

[63] Herrera N., Salaberria A. M., Mathew A. P., Oksman K.: Plasticized polylactic acid nanocomposite films with cellulose and chitin nanocrystals prepared using extrusion and compression molding with two cooling rates: Effects on mechanical, thermal and optical properties. Composites Part A: Applied Science and Manufacturing, 83, 89-97 (2016).

https://doi.org/10.1016/j.compositesa.2015.05.024

[64] Iyer K. A., Schueneman G. T., Torkelson J. M.: Cellulose nanocrystal/polyolefin biocomposites prepared by solid-state shear pulverization: Superior dispersion leading to synergistic property enhancements. Polymer, 56, 464-475 (2015).

https://doi.org/10.1016/j.polymer.2014.11.017

[65] Peddireddy K. R., Capron I., Nicolai T., Benyahia L.: Gelation kinetics and network structure of cellulose nanocrystals in aqueous solution. Biomacromolecules, 17, 3298-3304 (2016).

https://doi.org/10.1021/acs.biomac.6b01061

[66] Syverud K., Pettersen S. R., Draget K., Chinga-Carrasco G.: Controlling the elastic modulus of cellulose nanofibril hydrogels-scaffolds with potential in tissue engineering. Cellulose, 22, 473-481 (2015). https://doi.org/10.1007/s10570-014-0470-5

[67] Masruchin N., Park B-D., Causin V., Um I. C.: Characteristics of TEMPO-oxidized cellulose fibril-based hydrogels induced by cationic ions and their properties. Cellulose, 22, 1993-2010 (2015). https://doi.org/10.1007/s10570-015-0624-0

[68] Shivyari N. Y., Tajvidi M., Bousfield D. W., Gardner D. J.: Production and characterization of laminates of paper and cellulose nanofibrils. ACS Applied Materials and Interfaces, 8, 25520-25528 (2016). https://doi.org/10.1021/acsami.6b07655

[69] Zhang F., Ren H., Tong G., Deng Y.: Ultra-lightweight poly (sodium acrylate) modified TEMPO-oxidized cellulose nanofibril aerogel spheres and their superabsorbent properties. Cellulose, 23, 3665-3676 (2016). https://doi.org/10.1007/s10570-016-1041-8
[70] Yang X., Cranston E. D.: Chemically cross-linked cellulose nanocrystal aerogels with shape recovery and superabsorbent properties. Chemistry of Materials, 26, 6016-6025 (2014). https://doi.org/10.1021/cm502873c

[71] Tomić S., Kokol V., Mihajlović D., Mirčić A., Čolić M.: Native cellulose nanofibrills induce immune tolerance in vitro by acting on dendritic cells. Scientific Reports, 6, 1-14 (2016). https://doi.org/10.1038/srep31618

[72] Jackson J. K., Letchford K., Wasserman B. Z., Ye L., Hamad W. Y., Burt H. M.: The use of nanocrystalline cellulose for the binding and controlled release of drugs. International Journal of Nanomedicine, 6, 321-330 (2011). https://doi.org/10.2147/IJN.S16749

[73] Huq T., Vu K. D., Riedl B., Bouchard J., Han J., Lacroix M.: Development of probiotic tablet using alginate, pectin, and cellulose nanocrystals as excipients. Cellulose, 23, 1967-1978 (2016). https://doi.org/10.1007/s10570-016-0905-2

[74] Rees A., Powell L. C., Chinga-Carrasco G., Gethin D. T., Syverud K., Hill K. E., Thomas D. W.: 3D bioprinting of carboxymethylated-periodate oxidized nanocellulose constructs for wound dressing applications. BioMed Research International, 2015, 925757/1-925757/7 (2015). https://doi.org/10.1155/2015/925757

[75] Taheri A., Mohammadi M.: The use of cellulose nanocrystals for potential application in topical delivery of hydroquinone. Chemical Biology and Drug Design, 86, 102-106 (2015). https://doi.org/10.1111/cbdd.12466

[76] Yang J., Han C.: Mechanically viscoelastic properties of cellulose nanocrystals skeleton reinforced hierarchical composite hydrogels. ACS Applied Materials and Interfaces, 8, 25621-25630 (2016).

https://doi.org/10.1021/acsami.6b08834

[77] Jiang C., Oporto G. S., Zhong T., Jaczynski J.: TEMPO nanofibrillated cellulose as template for controlled release of antimicrobial copper from PVA films. Cellulose, 23, 713-722 (2016). https://doi.org/10.1007/s10570-015-0834-5

[78] Jin C., Jiang Y., Niu T., Huang J.: Cellulose-based material with amphiphobicity to inhibit bacterial adhesion by surface modification. Journal of Materials Chemistry, 22, 12562-12567 (2012).

https://doi.org/10.1039/C2JM31750H

[79] Teeguarden J. G., Hinderliter P. M., Orr G., Thrall B. D., Pounds J. G.: Particokinetics in vitro: Dosimetry considerations for in vitro nanoparticle toxicity assessments. Toxicological Sciences, 95, 300-312 (2007). https://doi.org/10.1093/toxsci/kfl165

[80] Roman M.: Toxicity of cellulose nanocrystals: A review. Industrial Biotechnology, 11, 25-33 (2015). https://doi.org/10.1089/ind.2014.0024

[81] Jacoby M.: Nano from the forest. Chemical and Engineering News, 92, 9-12 (2014). 